\title{
A New Conceptual Model for Slope-Infiltration
}

\author{
Renato Morbidelli ${ }^{1} * * \mathbb{D}$, Corrado Corradini $^{1}$, Carla Saltalippi ${ }^{1}$, Alessia Flammini ${ }^{1}$, \\ Jacopo Dari ${ }^{1}\left(\mathbb{D}\right.$ and Rao S. Govindaraju ${ }^{2}$ \\ 1 Department of Civil and Environmental Engineering, University of Perugia, via G. Duranti 93, \\ 06125 Perugia, Italy; corrado.corradini@unipg.it (C.C.); carla.saltalippi@unipg.it (C.S.); \\ alessia.flammini@unipg.it (A.F.); jacopo.dari@unifi.it (J.D.) \\ 2 Lyles School of Civil Engineering, Purdue University, West Lafayette, IN 47907, USA; govind@purdue.edu \\ * Correspondence: renato.morbidelli@unipg.it; Tel.: +39-075-5853620
}

Received: 21 February 2019; Accepted: 28 March 2019; Published: 1 April 2019

check for updates

\begin{abstract}
Rainfall infiltration modeling over surfaces with significant slopes is an unsolved problem. Even though water infiltration occurs over soil surfaces with noticeable gradients in most real situations, the typical mathematical models used were developed for infiltration over horizontal surfaces. In addition, recent investigations on infiltration over sloping surfaces have provided conflicting results, suggesting that our understanding of the process may still be lacking. In this study, our objective is to specifically examine if the surface water velocity that is negligible over near horizontal soil surfaces can affect the infiltration process over steep slopes. A new conceptual model representing a wide range of experimental results is proposed. The model represents water flow as an ensemble of infinitesimal "particles" characterized by specific velocities and assumes that only "particles" with velocity less than a threshold value can contribute to the infiltration process. The velocity distribution and the threshold value depend on slope and soil type, respectively. This conceptual model explains observed results and serves as a foundation for developing further experiments and refining models that offer more realistic representations of infiltration over sloping surfaces.
\end{abstract}

Keywords: hillslope hydrology; sloping surfaces; infiltration process; infiltration modeling; overland flow

\section{Introduction}

The process of infiltration of water into the soil is highly dependent on soil hydraulic properties that are generally variable in space, both in the vertical and horizontal directions. In natural conditions, the net rainfall reaching the soil is also affected by the vegetation cover that produces rainfall interception, sheltering the soil surface from the impact of falling drops. Vegetation also provides root systems that generate preferential subsurface flow paths.

Historically, solutions to infiltration problems have been represented through analytical, numerical, conceptual and empirical mathematical formulations. Analytical solutions provide estimates of infiltration rate or cumulative infiltration as functions of time, usually by simplifications on the soil water content profile during the study period. Powerful computers use numerical simulations of unsaturated soil domains in a single vertical direction or in multiple spatial dimensions, allowing for the use of complex initial and boundary conditions. Conceptual models try to balance the reduction of process complexity with a satisfactory representation of physical reality, obtaining simplified problem formulations. Finally, empirical infiltration models involve parameters fitted to the measured infiltration, but they have limited power as predictive tools because the same model cannot be used in different catchments.

The infiltration process has been deeply analyzed since early parts of last century at the point (or local) scale and lately also at a field scale, even though most models assumed a horizontal soil 
surface. At the local scale, when single storms are considered, classical equations (e.g., References [1-6]) or more recent formulations (e.g., Reference [7]) are generally adopted, while in the presence of events with consecutive soil water infiltration-redistribution cycles, conceptual/semi-analytical models, such as the one described by Reference [8], become necessary. Upscaling of these local models to obtain real (or field) models has been performed considering both vertically homogeneous [9-11] and layered [12] soils.

All the aforementioned models, as well as many others in the scientific literature, consider a soil surface that is oriented horizontally, while in most practical conditions the infiltration process occurs on surfaces with significant gradients [13]. The results obtained in the latter condition are not conclusive [14] and a physically-based approach with the ability to justify the experimental results needs to be developed. Table 1 shows a summary of theoretical (both analytical and conceptual) and experimental (carried out in both laboratory and field) studies dealing with the role of slope in infiltration. A comparison of these analyses, especially when carried out in natural fields, is confounded by several factors such as soil type and microtopography, rainfall intensity and duration, and presence of vegetation, to name a few. However, there exist laboratory experiments (e.g., Reference [15]) designed to exclude the abovementioned effects, showing a significant reduction of infiltration with slope, beyond the value expected when a steady state condition of soil saturation is assumed. This result is more pronounced for bare and clay soils rather than in vegetated and coarse-textured soils. Instead, most studies in Table 1 showing that infiltration increases with increasing slope were characterized by the formation of rills and/or a sealing layer. Nevertheless, some studies reported in Table 1 recommended the adoption of empirical corrections for the saturated hydraulic conductivity, $K_{s}$, but these corrections are not based on a theoretical approach and cannot be extended for general use.

Table 1. Studies dealing with the relation between slope and infiltration.

\begin{tabular}{|c|c|c|}
\hline Authors & Paper & Analysis Type \\
\hline \multicolumn{3}{|l|}{ Infiltration increase with increasing slope } \\
\hline Poesen & [16] & Experim. \\
\hline Janeau, Bricquet, Planchon, Valentin & [17] & Experim. \\
\hline Assouline, Ben-Hur & [18] & Experim. \\
\hline Chen, Young & [19] & Theor. \\
\hline Ribolzi, Patin, Bresson, Latsachack, Mouche, Sengtaheuanghoung, Silvera, ... & [20] & Experim \\
\hline \multicolumn{3}{|l|}{ Infiltration decrease with increasing slope } \\
\hline Nassif, Wilson & [21] & Experim. \\
\hline Sharma, Barron, Fernie & [22] & Experim. \\
\hline Philip & [23] & Theor. \\
\hline Fox, Bryan, Price & [24] & Experim. \\
\hline Chaplot, Le Bissonnais & [25] & Experim. \\
\hline Essig, Corradini, Morbidelli, Govindaraju & [26] & Experim. \\
\hline Patin, Mouche, Ribolzi, Chaplot, Sengtaheuanghoung, Latsachack, ... & [27] & Experim. \\
\hline Morbidelli, Saltalippi, Flammini, Cifrodelli, Corradini, Govindaraju & [15] & Experim. \\
\hline $\mathrm{Mu}, \mathrm{Yu}, \mathrm{Li}$, Xie, Tian, Liu, Zhao & [28] & Experim. \\
\hline Khan, Gong, Hu, Lai, Zheng, Justine, Azhar, Che, Zhang & [29] & Experim. \\
\hline Morbidelli, Saltalippi, Flammini, Cifrodelli, Picciafuoco, Corradini, ... & [30] & Experim. \\
\hline Wang, Chen, Yu & [31] & Theor. \\
\hline
\end{tabular}

Further theoretical developments are needed to understand the complex processes of infiltration over sloping surfaces and to obtain a model that is sufficiently representative of the available experimental results. A clear physical interpretation is required to support the prevailing hypothesis of decreasing infiltration with increasing slope and to indicate specific laboratory experiments needed to assess the proposed model.

The main objective of this paper is to present a conceptual model able to justify the reduction of infiltration (with increasing gradients) obtained in the absence of secondary disturbance effects. 
The basic idea of the proposed model would serve as a potential starting point to stimulate the development of new experiments to identify a model closer to physical reality.

\section{Basic Equations}

A study of the slope-infiltration interaction should be carried out by considering the coupling of the fundamental processes occurring at and immediately below the soil surface (Figure 1), i.e., infiltration and surface runoff.

rainfall
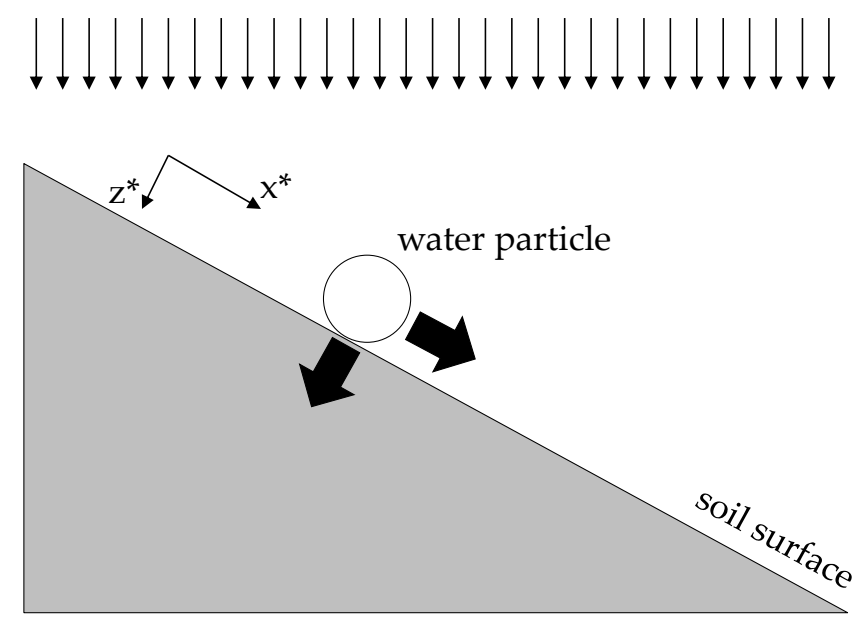

Figure 1. Schematic representation of the infiltration process over a sloping surface in a Cartesian coordinate system.

Under conditions of a homogeneous and isotropic soil and considering a smooth soil surface, the best theoretical representation of the involved processes can be obtained through the Richards equation for the sub-surface flow and the Saint-Venant equations for the overland flow. More specifically, the uni-dimensional Richards equation for a flat surface can be rewritten, in Cartesian coordinates $\left(x^{*}\right.$, $z^{*}$ ) shown in Figure 1, in the form (Reference [23]):

$$
\frac{\partial \theta}{\partial t}=\frac{\partial}{\partial z^{*}}\left[D \frac{\partial \theta}{\partial z^{*}}\right]-\frac{d K}{d \theta} \frac{\partial \theta}{\partial z^{*}} \cos \gamma
$$

where $t$ is the time, $\theta$ the volumetric soil water content, $K$ the hydraulic conductivity, $D$ the soil water diffusivity equal to $K(\theta)(d \psi(\theta) / d \theta)$ with $\psi$ soil suction head, and $\gamma$ the slope angle. Equation (1), under appropriate initial and boundary conditions, is identical to the classical Richards equation but with $K$ in the new coordinate system substituted by $K \cos \gamma$.

The Saint-Venant equations, with a lateral inflow $q_{l}$ per unit length that does not contribute any additional momentum to the flow, may be written as:

$$
\begin{gathered}
\frac{\partial Q}{\partial x^{*}}+\frac{\partial A}{\partial t}=q_{l}, \\
S_{f}=S_{0}-\frac{\partial h}{\partial x^{*}}-\frac{v}{g} \frac{\partial v}{\partial x^{*}}-\frac{1}{g} \frac{\partial v}{\partial t},
\end{gathered}
$$

where $Q$ is the discharge, $A$ the area of a cross-section, $v$ the velocity, $S_{f}$ the friction slope, $S_{0}$ the surface slope, $h$ the flow depth with reference to the bottom, and $g$ the gravity acceleration.

A straightforward analysis of Equations (1)-(3) along with initial and boundary conditions highlights that they cannot interact adequately. Specifically, the solution of the Richards equation may produce effects on the Saint-Venant equations (e.g., when the soil surface is saturated, the rainfall 
excess determined through Equation (1) and its boundary conditions could be identified with $q_{l}$, that moves along the slope according to Equations (2) and (3)). On the other hand, there is no possibility for the Saint-Venant equations to produce, from a mathematical point of view, any effect on the upper boundary conditions of the Richards equation, therefore precluding a possible interaction between the overland flow velocity and infiltration. Currently, we do not have a good way of defining the interface conditions between surface and subsurface flows at the soil surface.

\section{The Conceptual Model}

The basic element of the proposed model is inspired by the following observation. When a golf player is completing a hole, the last shot over the green has to be realized with a threshold velocity. If the ball is characterized by a velocity greater than this threshold value, it does not enter the hole (Figure 2) even though the direction is correct. A similar effect may be applicable to water moving on a porous surface.

Let us consider steady conditions with a small layer of overland flow generated by a rainfall rate, $r$. In line with the aforementioned abstraction, water "particles" can be roughly considered like balls running over a soil surface and drawn in the soil pores by gravity but in the presence of an interaction among the liquid water "particles". Furthermore, it is logical to consider that the arrival of new "particles" close to the pores depends on the persistence of overland flow under a given rainfall rate. The last condition assures the existence of "particles" that potentially may fall in the pores.

For a horizontal soil surface, considering that (1) all the "particles" may potentially enter the pores, because their velocity over the surface is practically equal to zero, and (2) the rainfall excess cannot enter the pores, the proposed model becomes unnecessary.

The interest in this conceptual model arises in case the soil surface possesses a slope, as in many natural conditions. With rainfall excess, water particles move downstream. Depending on friction slope, fluid viscosity, and other local conditions, each infinitesimal "particle" of water is characterized by a specific velocity (Figure 3). Consequently, it can be assumed that the "particles" move over the slope with different velocities that in the average increase with the distance from the soil surface.

The quantity "particle velocity" in the small layer that produces subsurface flow may be assumed as a stochastic variable characterized by a specific cumulative probability that for simplicity can be expressed through an exponential term. The last choice, somewhat arbitrary, could be changed without significant alterations of the proposed conceptual model. We have:

$$
P\left(v \leq v_{l}\right)=1-e^{-\lambda v_{l}}
$$

where $\lambda(>0)$ is the parameter of the probability distribution, $v$ the independent variable, and $v_{l}$ a specific value of $v$ representing the maximum velocity that allows infiltration of "particles" in a given pore.

Therefore "particles" with velocity less than $v_{l}$ may enter a specific pore, while "particles" with a velocity greater than $v_{l}$ continue their run over the surface. Only the fraction $P\left(v \leq v_{l}\right)$ may fall into the pore producing subsurface flow.

As for a golf player, the threshold velocity depends on the hole diameter. In the proposed conceptual model, $v_{l}$ depends on the pore dimensions that are linked with soil texture and particle layout in the soil matrix. This means that $v_{l}$ may be linked with $K_{s}$. Furthermore, $P\left(v \leq v_{l}\right)$ changes with increasing slope because of the increasing velocity of "particles". Consequently, for steeper slopes, the probability to have values of $v$ lower than $v_{l}$ decreases and Equation (4) suggests that $\lambda$ becomes smaller (Figure 4). The probability $P\left(v \leq v_{l}\right)$ is also influenced, particularly in the presence of vegetation, by the surface roughness, but bare soils are considered here. 

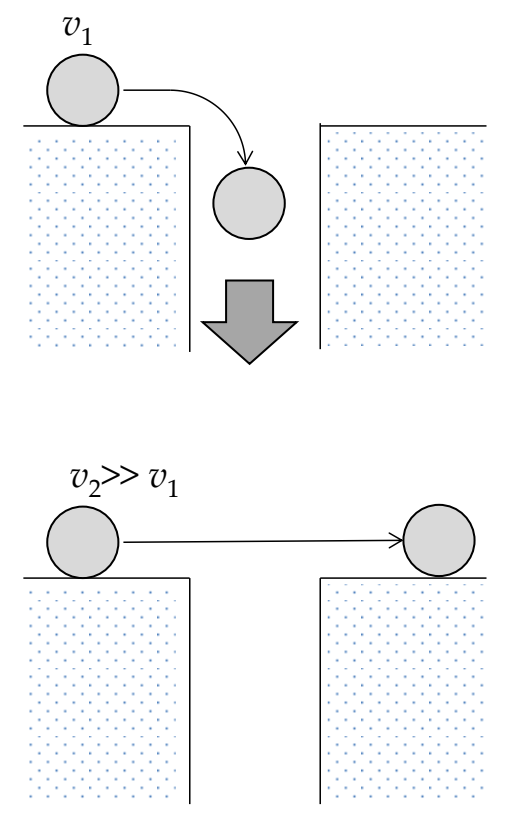

Figure 2. Movement of balls in a golf game: Balls can fall into the hole or not depending on their velocity $\left(v_{2}>>v_{1}\right)$.

Hence, a given surface slope determines a specific $P\left(v \leq v_{l}\right)$ through a specific $\lambda$ value, while the soil structure, characterized by a well-known $K_{s}$, affects the threshold velocity $v_{l}$. As a final result, under steady conditions, infiltration of water into a slope, $K_{s e}$, can be obtained as $K_{s e}=K_{s} \times P\left(v<v_{l}\right)$, with $K_{s}$ that represents the saturated hydraulic conductivity for a horizontal soil surface. The quantity $K_{s e}$ may be considered as an effective saturated hydraulic conductivity depending on the soil gradient.

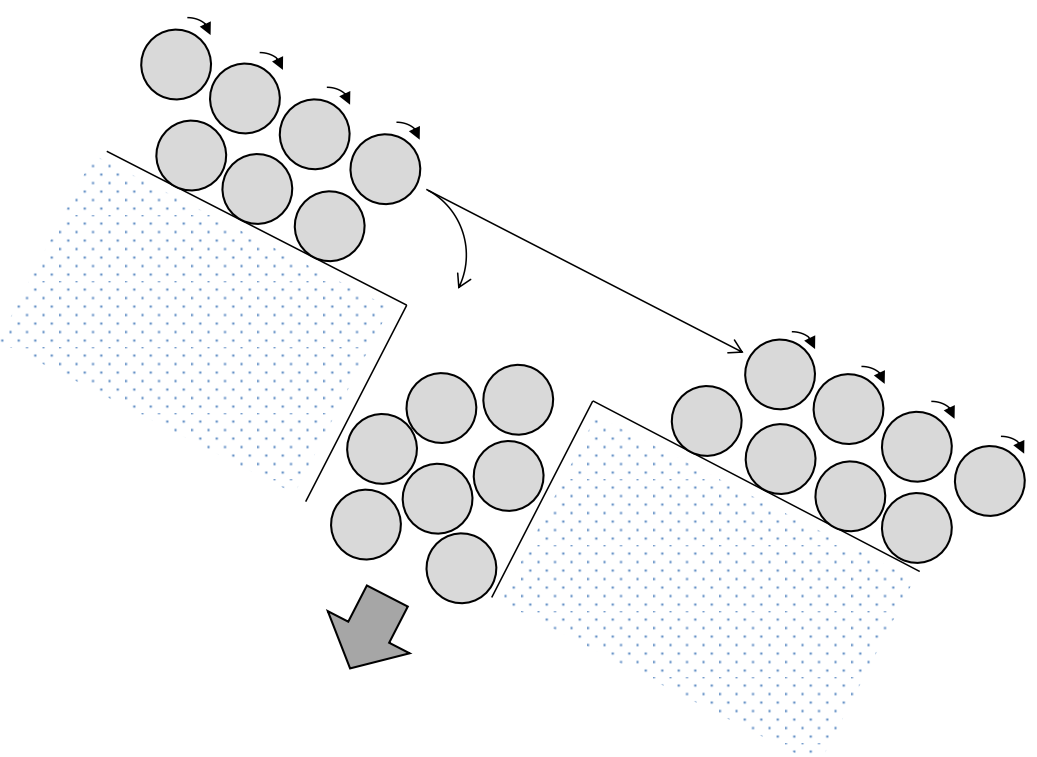

Figure 3. Soil surface with significant slope and "particles" characterized by various velocities. 


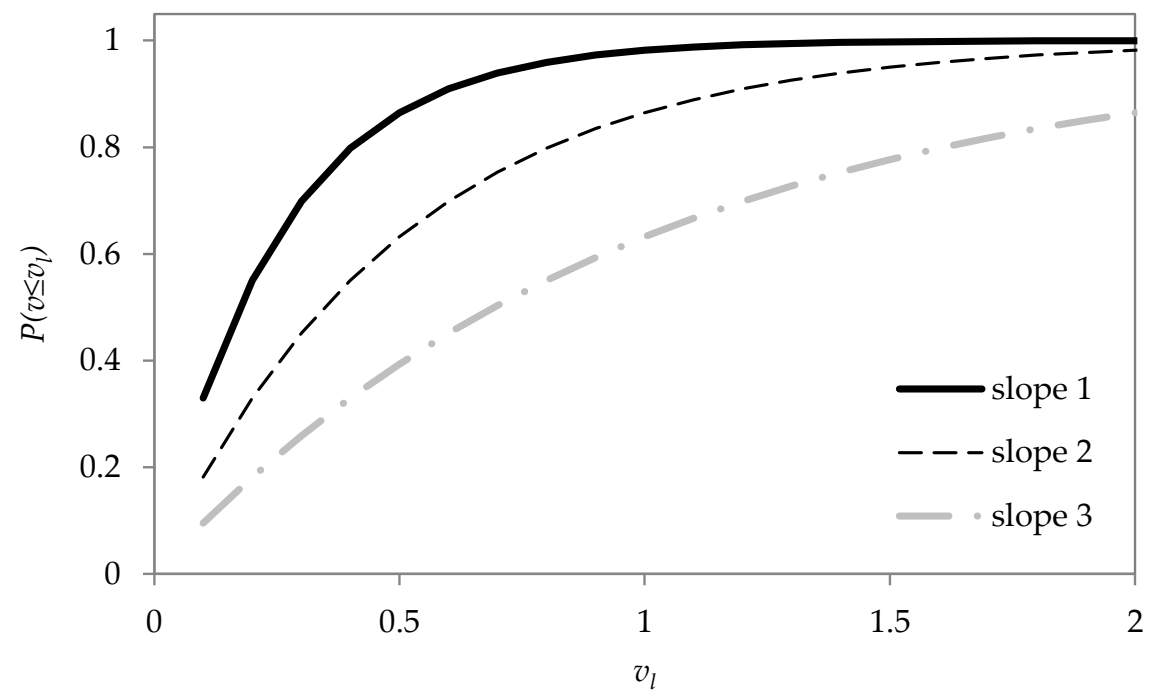

Figure 4. Example of three different cumulative probability functions of the "particle" velocities associated to different slopes (slope $1<$ slope $2<$ slope 3 ) with the corresponding $\lambda$ values in Equation (4) equal to 4,2 , and $1 \mathrm{~s} / \mathrm{cm}$, respectively.

\section{Model Parameters}

The key parameters of the model are the threshold velocity, $v_{l}$, and the decay parameter of the cumulative probability, $\lambda$. A simple approach to obtain their values can be to fix one of them and to determine the other using a calibration procedure based on the use of experimental data. As discussed above, the threshold velocity is physically linked with the pore diameters and therefore with soil texture and particle layout, which in turn influence $K_{s}$. We assume $v_{l}$ equal to $K_{s}$ even though this choice will affect the estimate of $\lambda$, that should depend only on the slope while its value obtained through calibration will also adjust for this non-optimal hypothesis. Really, this assumption does not reflect the physical reality because $v_{l}$ depends on the pore diameters that in a given soil is a random variable and therefore should be represented by a stochastic approach. Therefore, our rough simplification with a sole value of $v_{l}$ equal to $K_{s}$ is equivalent to considering all soil pores characterized by a representative diameter.

\section{Experimental System}

The calibration process of the $\lambda$ parameter requires the use of results obtained by laboratory experiments carried out through a physical model [26]. The adopted equipment is $1.52 \mathrm{~m}$ long, $1.22 \mathrm{~m}$ wide, and $0.78 \mathrm{~m}$ deep, with a tray angle adjustable up to $30^{\circ}$. As it can be seen in Figure 5, all boundaries of the physical model are impermeable except for the soil surface. A small gravel layer (with thickness $7 \mathrm{~cm}$ ) is placed at the bottom of the soil. Surface and percolated/deep flows are measured by two calibrated sensors based on a tipping-bucket mechanism. Different steady rainfall rates, sufficiently uniform over the slope with values up to $80 \mathrm{~mm} \mathrm{~h}^{-1}$, can be generated using special sprinklers, a pump, and a manual manometer. The various natural soils used for the experiments are characterized by the grain size distributions shown in Figure 6 with saturated hydraulic conductivity associated to horizontal surface, $K_{s}$, equal to $2.93 \mathrm{~mm} \mathrm{~h}^{-1}, 3.20 \mathrm{~mm} \mathrm{~h}^{-1}, 10.37 \mathrm{~mm} \mathrm{~h}^{-1}$ and $17.00 \mathrm{~mm} \mathrm{~h}^{-1}$ for soil 1, soil 2, soil 3, and soil 4, respectively [26,32-36]. Each experimental run lasted more than $24 \mathrm{~h}$, and the rainfall that was applied during the first $8-10 \mathrm{~h}$ produced extended periods with steady conditions in the absence of direct rainfall infiltration. Before the beginning of each experiment, rainfall was applied in order to have high soil water content at any depth. Furthermore, in the time period between two successive experiments, the surface water content was kept sufficiently high in order to avoid the formation of cracks. The measurements of deep flow for different gradients obtained under 
steady conditions are assumed equal to $K_{s e}$. Soil erosion did not affect the experiments as checked by an analysis of the surface water cloudiness.

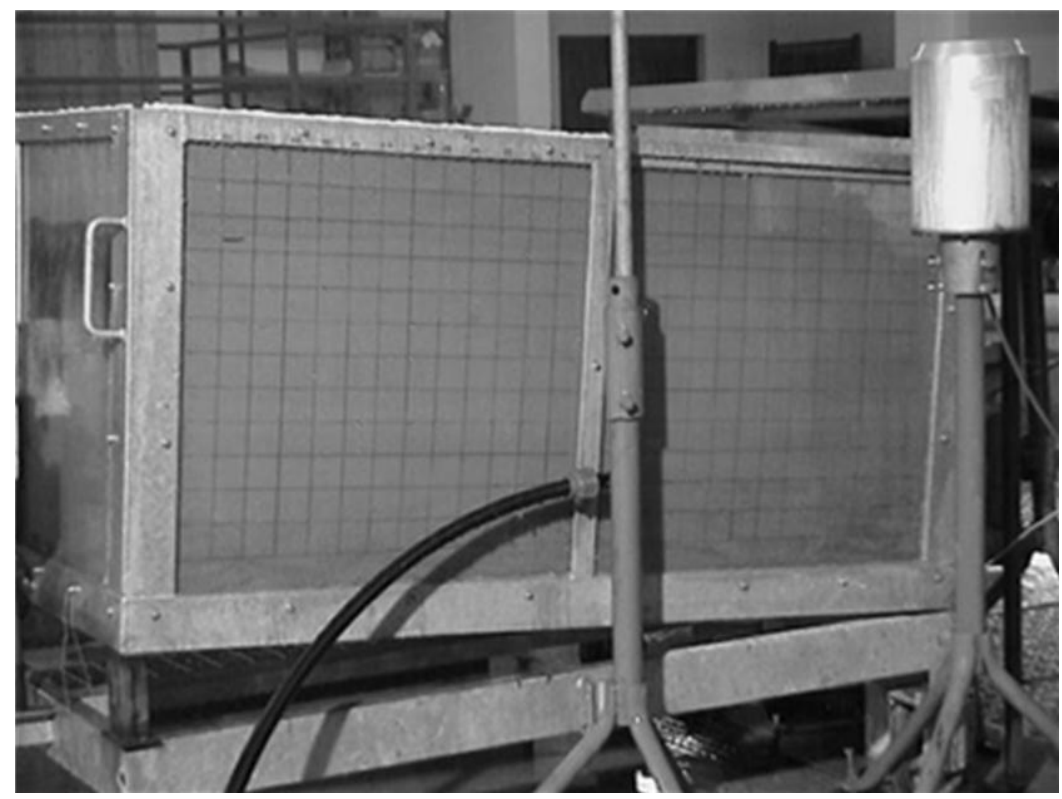

Figure 5. A view of the physical model adopted in the laboratory experiments for slope-infiltration studies.

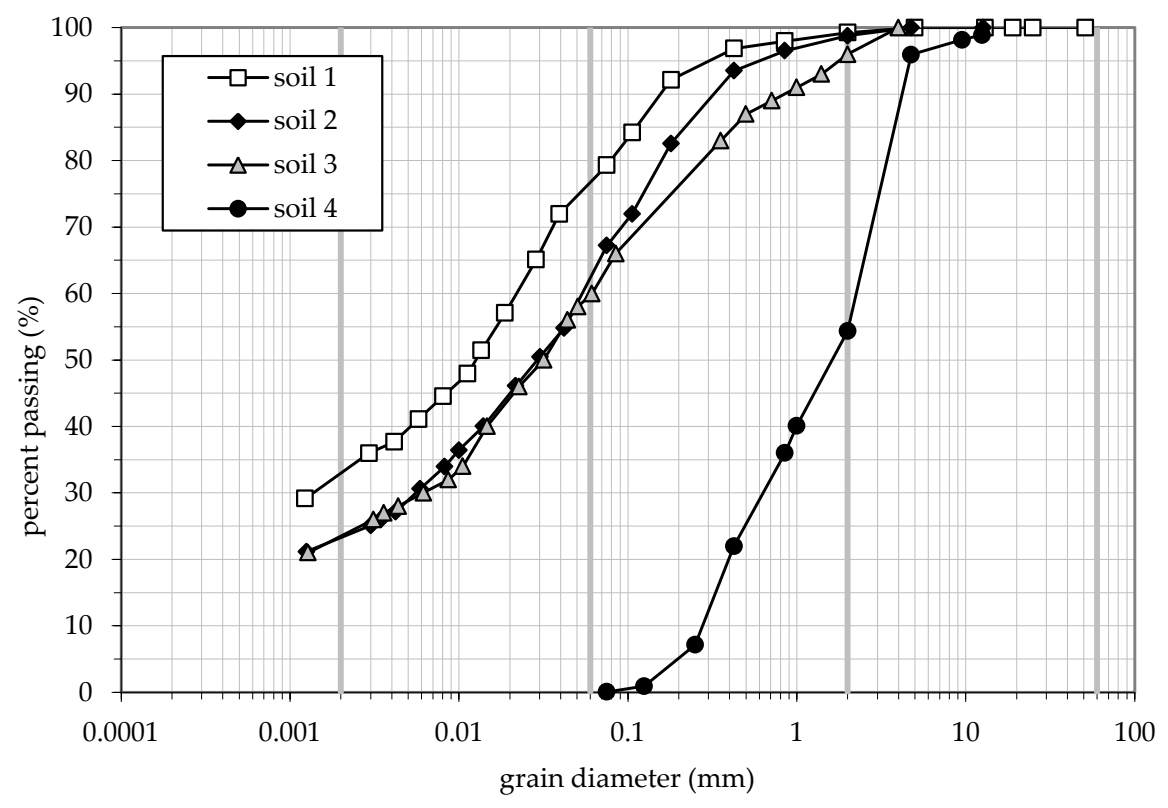

Figure 6. Grain size distribution of the soils used in the laboratory experiments.

\section{Analysis of Results}

Some experimental results on the laboratory system described above were deduced by Reference [26]. Three natural soils were used in different sets of laboratory experiments. The first set of experiments (performed by using soil 1 of Figure 6, labeled as "Clay Loam" soil according to USDA soil classification) consisted of 24 trials with slopes in the range $1^{\circ}-15^{\circ}$ and rainfall rates in the range 10-20 $\mathrm{mm} \mathrm{h}^{-1}$. The second set (by using soil 2 of Figure 6, labeled as "Loam" soil by USDA) consisted of 8 trials with slopes and rainfall rates in the ranges $1^{\circ}-15^{\circ}$ and $10-15 \mathrm{~mm} \mathrm{~h}^{-1}$, respectively. Finally, the third set of experiments (soil 3 of Figure 6, labeled as "Sandy Loam" soil by USDA) consisted of 18 trials where slopes and rainfall rates were in the ranges $1^{\circ}-10^{\circ}$ and $20-30 \mathrm{~mm} \mathrm{~h}^{-1}$, respectively. As it 
can be seen, the adopted surface slopes and soil types were not exhaustive because they didn't involve slopes exceeding $15^{\circ}$ and didn't consider a very coarse textured soil.

Therefore, a new set of experiments has been carried out with a fourth soil type (soil 4 of Figure 6, labeled as "Sandy" soil by USDA) considering the surface slope in the range $10^{\circ}-26^{\circ}$ and a very heavy rainfall rate (about $60 \mathrm{~mm} \mathrm{~h}^{-1}$ ). The main results obtained by these new experiments are summarized in Table 2 and confirm that for a fixed reference rainfall rate the slope gradient has a negative influence on the steady deep flow. These results are consistent with those of Reference [26]. Even if they refer to conditions dominated by gravitational effects, the theoretical formulations earlier proposed provide incorrect simulations.

Table 2. Steady surface and deep flows for different laboratory slope gradients under a rainfall rate of about $60 \mathrm{~mm} \mathrm{~h}^{-1}$. Soil 4 of Figure 6 is shown.

\begin{tabular}{ccccccc}
\hline \multirow{2}{*}{$\begin{array}{c}\text { Experiment } \\
\text { Number }\end{array}$} & Slope $\left.\mathbf{(}^{\circ}\right)$ & $\begin{array}{c}\text { Average Rainfall } \\
\text { Rate }\left(\mathbf{m m ~ h} \mathbf{~ h}^{-\mathbf{1}}\right)\end{array}$ & \multicolumn{2}{c}{ Steady Surface Flow } & \multicolumn{2}{c}{ Steady Deep Flow } \\
\cline { 4 - 7 } & & 59.10 & 46.30 & 78.34 & 12.80 & 21.66 \\
\hline 1 & 10 & 59.36 & 48.36 & 81.46 & 11.00 & 18.54 \\
2 & 17 & 61.10 & 52.60 & 86.09 & 8.50 & 13.91 \\
3 & 21 & 62.60 & 55.40 & 88.50 & 7.20 & 11.50 \\
4 & 26 & &
\end{tabular}

The estimate of $\lambda$ requires us to subdivide the experiments selected here, excluding those carried out with almost horizontal soil surface that have been used for the determination of $K_{s}$ (14 experiments with slope equal to $1^{\circ}$, as specified in References [15] and [26]), into two groups (with comparable general features) to be used in the calibration and validation phases, respectively (Table 3 ).

Through an inverse procedure, for each laboratory experiment of the selected calibration set a specific $\lambda$ parameter can be derived from Equation (4). Specifically, as a first approximation, $v_{l}$ is assumed to be equal to $K_{s}$ because a better approach closer to physical reality would require a joint solution of Equations (1) and (2), which is blocked, as pointed out in Section 2, by the difficult representation of their interaction. Then, the term on the left, $P\left(v \leq v_{l}\right)$, is expressed by the ratio between the observed steady deep flow, $d_{f}$, and $K_{s}$. Therefore, $\lambda$ is the only unknown quantity in Equation (4).

Considering the laboratory experiments 1-20 of Table 3 , the following general relation between slope and $\lambda$ has been obtained:

$$
\lambda=0.9861 e^{-0.139 \times \text { slope }},
$$

where the slope is expressed in $\left(^{\circ}\right)$. Figure 7 shows the accuracy level of this interpolating function. The scattering of the $\lambda$ values at given slope angles may be linked with other influential factors not represented in our approach such as, for example, the surface roughness that is expected to be variable from bare soil to another because of their different structure.

The model validation has been made using the laboratory experiments $21-40$ of Table 3 , through the relative error of the steady deep flow, $\varepsilon_{d f}$, defined as follows:

$$
\varepsilon_{d f}=100 \frac{\left(K_{s e}-d_{f}\right)}{d_{f}}
$$

with $K_{s e}$ given by:

$$
K_{s e}=K_{s}\left(1-e^{-\lambda K_{s}}\right) .
$$

As shown in Table $4, \varepsilon_{d f}$ is within the range of $-28.9 \% /+22.6 \%$ with an algebraic mean value of $1.0 \%$ (or $9.9 \%$ when the absolute value of each $\varepsilon_{d f}$ is considered). In a few cases, the relative error is significant, and therefore, we note that the steady deep flow is generally well reproduced by the proposed model (see also Figure 8). 
Finally, from the experimental results, it comes out that increasing the rainfall rate becomes larger for the steady surface flow while the steady deep flow experiences minor changes. More specifically, combining for each slope the results shown in Table 4 for the steady surface and deep flow with the values of rainfall rate given in Table 3 , it can be deduced as doubled values of rainfall rate and surface runoff do not determine in the average a clear trend of the deep flow. This outcome may be ascribed to the fact that increasing the water depth on the surface increases its average velocity on the slope, but the velocity of the small layer that affects infiltration does not experience significant variation.

Table 3. Main characteristics of the selected laboratory experiments (from Reference [26] and Table 2), subdivided into calibration and validation sets.

\begin{tabular}{|c|c|c|c|}
\hline Order Number & Experiment Identification & Slope $\left(^{\circ}\right)$ & Average Rainfall $\left(\mathrm{mm} \mathrm{h}^{-1}\right)$ \\
\hline \multicolumn{4}{|c|}{ Calibration experiments } \\
\hline 1 & soil 1, exp 3 [26] & 5 & 9.74 \\
\hline 2 & soil 1, exp 4 [26] & 5 & 15.16 \\
\hline 3 & soil 1, exp 19 [26] & 5 & 20.49 \\
\hline 4 & soil 1, exp 5 [26] & 10 & 10.07 \\
\hline 5 & soil 1, exp 6 [26] & 10 & 14.62 \\
\hline 6 & soil 1, exp 21 [26] & 10 & 20.04 \\
\hline 7 & soil 1, exp 11 [26] & 15 & 8.85 \\
\hline 8 & soil 1, exp 12 [26] & 15 & 13.18 \\
\hline 9 & soil 1, exp $23[26]$ & 15 & 20.49 \\
\hline 10 & soil 2, exp 3 [26] & 5 & 9.77 \\
\hline 11 & soil 2, exp 5 [26] & 10 & 9.91 \\
\hline 12 & soil 2, exp $7[26]$ & 15 & 9.96 \\
\hline 13 & soil 3, exp 15 [26] & 5 & 18.82 \\
\hline 14 & soil 3, exp 5 [26] & 5 & 25.86 \\
\hline 15 & soil 3, exp 7 [26] & 5 & 32.12 \\
\hline 16 & soil 3, exp 17 [26] & 10 & 18.61 \\
\hline 17 & soil 3, exp 9 [26] & 10 & 25.82 \\
\hline 18 & soil 3, exp 11 [26] & 10 & 30.37 \\
\hline 19 & soil 4, exp 3 (Table 2 ) & 21 & 61.10 \\
\hline 20 & soil 4 , exp 4 (Table 2) & 26 & 62.60 \\
\hline \multicolumn{4}{|c|}{ Validation experiments } \\
\hline 21 & soil 1, exp 13 [26] & 5 & 9.55 \\
\hline 22 & soil 1, exp 14 [26] & 5 & 13.81 \\
\hline 23 & soil 1, exp 20 [26] & 5 & 20.28 \\
\hline 24 & soil 1, exp 9 [26] & 10 & 9.11 \\
\hline 25 & soil 1, exp 10 [26] & 10 & 14.56 \\
\hline 26 & soil 1, exp $22[26]$ & 10 & 20.02 \\
\hline 27 & soil 1, exp 7 [26] & 15 & 9.85 \\
\hline 28 & soil 1, exp 8 [26] & 15 & 14.30 \\
\hline 29 & soil 1, exp 24 [26] & 15 & 19.84 \\
\hline 30 & soil 2, exp 4 [26] & 5 & 15.92 \\
\hline 31 & soil 2, exp 6 [26] & 10 & 15.02 \\
\hline 32 & soil 2, exp 8 [26] & 15 & 13.90 \\
\hline 33 & soil 3, exp 16 [26] & 5 & 18.29 \\
\hline 34 & soil 3, exp 6 [26] & 5 & 25.83 \\
\hline 35 & soil 3, exp 8 [26] & 5 & 32.31 \\
\hline 36 & soil 3, exp 18 [26] & 10 & 18.36 \\
\hline 37 & soil 3, exp 10 [26] & 10 & 25.87 \\
\hline 38 & soil 3, exp 12 [26] & 10 & 31.34 \\
\hline 39 & soil 4, exp 1 (Table 2 ) & 10 & 59.10 \\
\hline 40 & soil 4, exp 2 (Table 2 ) & 17 & 59.36 \\
\hline
\end{tabular}




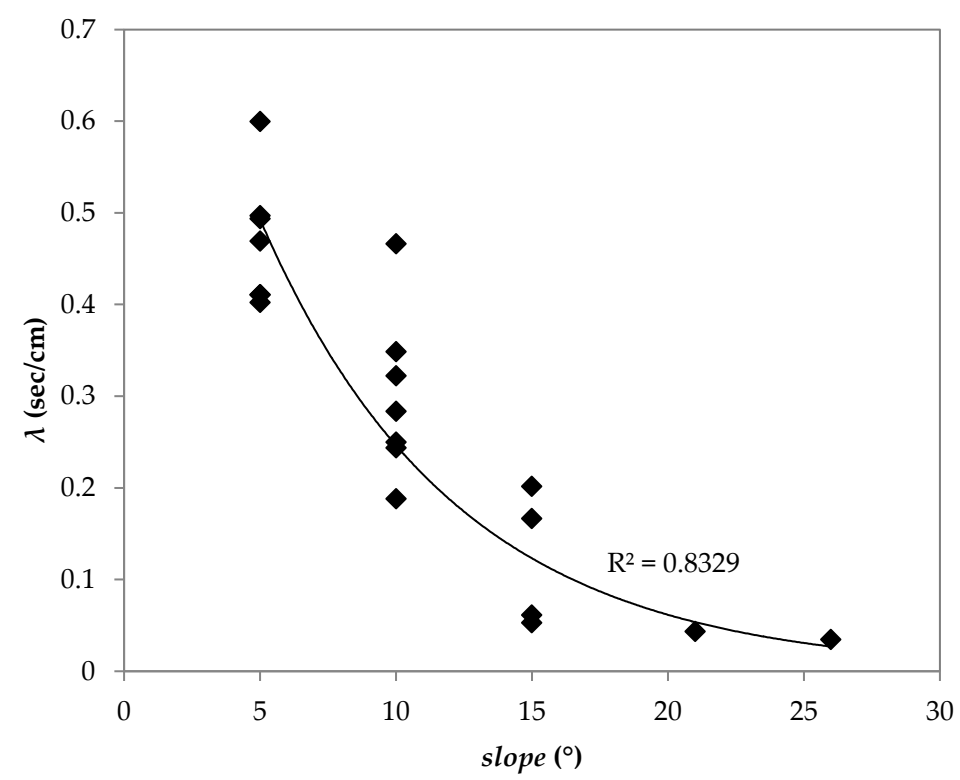

Figure 7. The $\lambda$ parameter of Equation (4) obtained for the calibration experiments performed at the different slope angles. The best interpolating function is also plotted.

Table 4. Model validation synthesized through the relative error of the steady deep flow, $\varepsilon_{d f}$ (Equations (6) and (7)).

\begin{tabular}{|c|c|c|c|c|c|}
\hline Order Number & Experiment Identification & Slope $\left(^{\circ}\right)$ & $\begin{array}{c}\text { Steady Deep } \\
\text { Flow }\left(\mathrm{mm} \mathrm{h}^{-1}\right)\end{array}$ & $\begin{array}{c}K_{s} \times P\left(v<v_{l}\right) \\
\left(\mathrm{mm} \mathrm{h}^{-1}\right)\end{array}$ & $\varepsilon_{d f}(\%)$ \\
\hline 21 & soil 1, exp 13 [26] & 5 & 2.46 & 2.24 & -9.1 \\
\hline 22 & soil 1, exp 14 [26] & 5 & 2.32 & 2.24 & -3.6 \\
\hline 23 & soil 1, exp 20 [26] & 5 & 2.11 & 2.24 & 6.0 \\
\hline 24 & soil 1, exp 9 [26] & 10 & 1.38 & 1.50 & 8.9 \\
\hline 25 & soil 1, exp 10 [26] & 10 & 1.24 & 1.50 & 21.2 \\
\hline 26 & soil 1, exp 22 [26] & 10 & 1.79 & 1.50 & -16.0 \\
\hline 27 & soil 1, exp 7 [26] & 15 & 0.91 & 0.88 & -2.9 \\
\hline 28 & soil 1, exp 8 [26] & 15 & 0.77 & 0.88 & 14.8 \\
\hline 29 & soil 1, exp 24 [26] & 15 & 0.77 & 0.88 & 14.8 \\
\hline 30 & soil 2, exp 4 [26] & 5 & 2.54 & 2.54 & -0.1 \\
\hline 31 & soil 2, exp 6 [26] & 10 & 2.27 & 1.74 & -23.3 \\
\hline 32 & soil 2, exp 8 [26] & 15 & 1.46 & 1.04 & -28.9 \\
\hline 33 & soil 3, exp 16 [26] & 5 & 9.63 & 10.31 & 7.0 \\
\hline 34 & soil 3, exp 6 [26] & 5 & 10.33 & 10.31 & -0.2 \\
\hline 35 & soil 3, exp 8 [26] & 5 & 10.25 & 10.31 & 0.6 \\
\hline 36 & soil 3, exp 18 [26] & 10 & 9.46 & 9.56 & 1.0 \\
\hline 37 & soil 3, exp 10 [26] & 10 & 9.54 & 9.56 & 0.2 \\
\hline 38 & soil 3, exp 12 [26] & 10 & 10.05 & 9.56 & -4.9 \\
\hline 39 & soil 4, exp 1 (Table 2$)$ & 10 & 12.80 & 15.68 & 22.6 \\
\hline 40 & soil 4, exp 2 (Table 2) & 17 & 11.00 & 12.38 & 12.5 \\
\hline
\end{tabular}




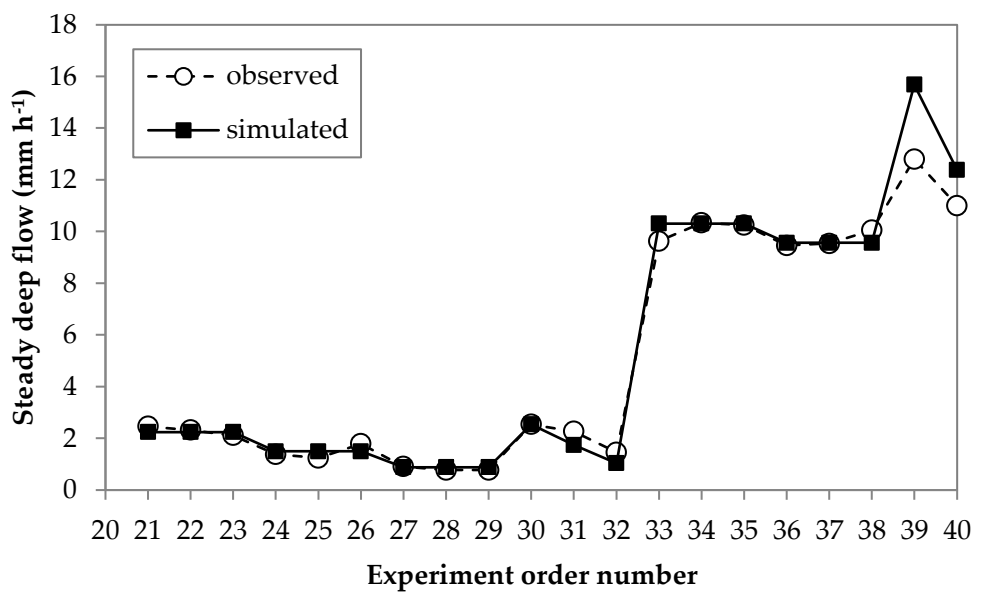

Figure 8. Comparison of the observed and simulated steady deep flow for the different validation experiments.

\section{Conclusions}

The starting point of this work is that the infiltration process on sloping surfaces observed in many laboratory experiments is not correctly represented by the existing theoretical modeling efforts.

On the basis of the main outcomes of this analysis performed using 54 laboratory experiments and a conceptual model, the following insights can be derived:

- The proposed conceptual model can represent most laboratory experimental results obtained for bare soils in the absence of secondary disturbance effects due to erosion and formation of a sealing layer.

- According to this model, the "particles" of water moving above a sloping surface are characterized by velocities considered as realizations of a stochastic variable with a cumulative probability function expressed through an exponential term.

- Only water "particles" with velocity below a threshold value may contribute to the infiltration process.

- In practical terms, from the knowledge of surface slope, as well as of soil texture and particles layout (both linked to $K_{s}$ ), a cumulative probability function $P\left(v<v_{l}\right)$ may be derived. The behavior of different soil types is represented through the associated $K_{s}$ values.

- Under steady state conditions, the infiltrating water is given by an effective saturated hydraulic conductivity expressed by $K_{s} \times P\left(v<v_{l}\right)$.

- Processes related to the fluid viscosity are not explicitly considered.

- The surface roughness plays an important role on the surface flow velocity. When particular vegetation is present (e.g., grassy soil) a specific calibration of $\lambda$, which is the unique parameter of the proposed model, is necessary. On this basis to generalize the model, new laboratory experiments with different surface types should be performed.

- This work supports the idea that the infiltration process on a sloping surface is highly conditioned by the surface flow velocity. When the surface slope increases the water speed increases, while infiltration decreases. An extension of this simple concept could be useful to further our knowledge of the infiltration process over sloping surfaces even under unsteady conditions when $K_{s e}$ could be used to substitute $K_{s}$.

Author Contributions: Laboratory experiments, numerical analyses, investigation, writing-original draft preparation and writing - review and editing, R.M., C.C., C.S., A.F., J.D. and R.S.G.

Funding: This research was partly financed by the Italian Ministry of Education, University and Research (PRIN 2015).

Acknowledgments: The authors are thankful to A.G. Del Prete for his technical assistance. 
Conflicts of Interest: The authors declare no conflict of interest.

\section{References}

1. Green, W.A.; Ampt, G.A. Studies on soil physics: 1. The flow of air and water through soils. J. Agric. Sci. 1911, 4, 1-24. [CrossRef]

2. Horton, R.E. An approach toward a physical interpretation of infiltration-capacity. Soil Sci. Soc. Am. J. 1940, 5, 399-417. [CrossRef]

3. Philip, J.R. The theory of infiltration: 1. The infiltration equation and its solution. Soil Sci. 1957, 83, 345-357. [CrossRef]

4. Philip, J.R. The theory of infiltration: 2. The profile at infinity. Soil Sci. 1957, 83, 435-448. [CrossRef]

5. Philip, J.R. The theory of infiltration: 4. Sorptivity algebraic infiltration equation. Soil Sci. 1957, 84, 257-264. [CrossRef]

6. Smith, R.E.; Parlange, J.-Y. A parameter-efficient hydrologic infiltration model. Water Resour. Res. 1978, 14, 533-538. [CrossRef]

7. Corradini, C.; Morbidelli, R.; Flammini, A.; Govindaraju, R.S. A parameterized model for local infiltration in two-layered soils with a more permeable upper layer. J. Hydrol. 2011, 396, 221-232. [CrossRef]

8. Corradini, C.; Melone, F.; Smith, R.E. A unified model for infiltration and redistribution during complex rainfall patterns. J. Hydrol. 1997, 192, 104-124. [CrossRef]

9. Smith, R.E.; Goodrich, D.C. Model for rainfall excess patterns on randomly heterogeneous area. J. Hydrol. Eng. 2000, 5, 355-362. [CrossRef]

10. Govindaraju, R.S.; Morbidelli, R.; Corradini, C. Areal infiltration modeling over soils with spatially-correlated hydraulic conductivities. J. Hydrol. Eng. 2001, 6, 150-158. [CrossRef]

11. Corradini, C.; Govindaraju, R.S.; Morbidelli, R. Simplified modelling of areal average infiltration at the hillslope scale. Hydrol. Proc. 2002, 16, 1757-1770. [CrossRef]

12. Corradini, C.; Flammini, A.; Morbidelli, R.; Govindaraju, R.S. A conceptual model for infiltration in two-layered soils with a more permeable upper layer: From local to field scale. J. Hydrol. 2011, 410, 62-72. [CrossRef]

13. Beven, K.J. Rainfall-Runoff Modelling; John Wiley \& Sons: Chichester, UK, 2002; ISBN 978-0-470-71459-1.

14. Morbidelli, R.; Saltalippi, C.; Flammini, A.; Govindaraju, R.S. Role of slope on infiltration: A review. J. Hydrol. 2018, 557, 878-886. [CrossRef]

15. Morbidelli, R.; Saltalippi, C.; Flammini, A.; Cifrodelli, M.; Corradini, C.; Govindaraju, R.S. Infiltration on sloping surfaces: Laboratory experimental evidence and implications for infiltration modelling. J. Hydrol. 2015, 523, 79-85. [CrossRef]

16. Poesen, J. The influence of slope angle on infiltration rate and hortonian overland flow volume. Z. Geomorphol. 1984, 49, 117-131.

17. Janeau, J.L.; Bricquet, J.P.; Planchon, O.; Valentin, C. Soil crusting and infiltration on steep slopes in northern Thailand. Europ. J. Soil Sci. 2003, 54, 543-553. [CrossRef]

18. Assouline, S.; Ben-Hur, M. Effects of rainfall intensity and slope gradient on the dymanics of interrill erosion during soil surface sealing. Catena 2006, 66, 211-220. [CrossRef]

19. Chen, L.; Young, M.H. Green-Ampt infiltration model for sloping surfaces. Water Resour. Res. 2006, 42, W07420. [CrossRef]

20. Ribolzi, O.; Patin, J.; Bresson, L.; Latsachack, K.; Mouche, E.; Sengtaheuanghoung, O.; Silvera, N.; Thiébaux, J.P.; Valentin, C. Impact of slope gradient on soil surface features and infiltration on steep slopes in northern Laos. Geomorphology 2011, 127, 53-63. [CrossRef]

21. Nassif, S.H.; Wilson, E.M. The influence of slope and rain intensity on runoff and infiltration. Hydrol. Sci. Bull. 1975, 20, 539-553. [CrossRef]

22. Sharma, K.; Singh, H.; Pareek, O. Rainwater infiltration into a bar loamy sand. Hydrol. Sci. J. 1983, $28,417-424$. [CrossRef]

23. Philip, J.R. Hillslope infiltration: Planar slopes. Water Resour. Res. 1991, 27, 109-117. [CrossRef]

24. Fox, D.M.; Bryan, R.B.; Price, A.G. The influence of slope angle on final infiltration rate for interrill conditions. Geoderma 1997, 80, 181-194. [CrossRef] 
25. Chaplot, V.; Le Bissonais, Y. Field measurements of interrill erosion under different slopes and plot sizes. Earth Surf. Process. Landf. 2000, 25, 145-153. [CrossRef]

26. Essig, E.T.; Corradini, C.; Morbidelli, R.; Govindaraju, R.S. Infiltration and deep flow over sloping surfaces: Comparison of numerical and experimental results. J. Hydrol. 2009, 374, 30-42. [CrossRef]

27. Patin, J.; Mouche, E.; Ribolzi, O.; Chaplot, V.; Sengtaheuanghoung, O.; Latsachak, K.O.; Soulileuth, B.; Valentin, C. Analysis of runoff production at the plot scale during a long-term survey of a small agricultural catchment in Lao PDR. J. Hydrol. 2012, 426-427, 79-92. [CrossRef]

28. Mu, W.; Yu, F.; Li, C.; Xie, Y.; Tian, J.; Liu, J.; Zhao, N. Effects of rainfall intensity and slope gradient on runoff and soil moisture content on different growing stages of spring maize. Water 2015, 7, 2990-3008. [CrossRef]

29. Khan, M.N.; Gong, Y.; Hu, T.; Lal, R.; Zheng, J.; Justine, M.F.; Azhar, M.; Che, M.; Zhang, H. Effect of slope, rainfall intensity and mulch on erosion and infiltration under simulated rain on purple soil of south-western Sichuan province, China. Water 2016, 8, 528. [CrossRef]

30. Morbidelli, R.; Saltalippi, C.; Flammini, A.; Cifrodelli, M.; Picciafuoco, T.; Corradini, C.; Govindaraju, R.S. Laboratory investigation on the role of slope on infiltration over grassy soils. J. Hydrol. 2016, 543, 542-547. [CrossRef]

31. Wang, J.; Chen, L.; Yu, Z. Modeling rainfall infiltration on hillslopes using flux-concentration relation and time compression approximation. J. Hydrol. 2018, 557, 243-253. [CrossRef]

32. Melone, F.; Corradini, C.; Morbidelli, R.; Saltalippi, C. Laboratory experimental check of a conceptual model for infiltration under complex rainfall patterns. Hydrol. Proc. 2006, 20, 439-452. [CrossRef]

33. Melone, F.; Corradini, C.; Morbidelli, R.; Saltalippi, C.; Flammini, A. Comparison of theoretical and experimental soil moisture profiles under complex rainfall patterns. J. Hydrol. Eng. 2008, 13, 1170-1176. [CrossRef]

34. Morbidelli, R.; Corradini, C.; Saltalippi, C.; Govindaraju, R.S. Laboratory experimental investigation of infiltration by the run-on process. J. Hydrol. Eng. 2008, 13, 1187-1192. [CrossRef]

35. Morbidelli, R.; Saltalippi, C.; Flammini, A.; Cifrodelli, M.; Corradini, C. A laboratory experimental system for infiltration studies. Hydrol. Res. 2017, 48, 741-748. [CrossRef]

36. Morbidelli, R.; Saltalippi, C.; Flammini, A.; Rossi, E.; Corradini, C. Soil water content vertical profiles under natural conditions: Matching of experiments and simulations by a conceptual model. Hydrol. Proc. 2014, 28, 4732-4742. [CrossRef] 